\title{
Liquid networks and the metaphysics of flux: Ontologies of flow in an age of speed and mobility
}

Thomas Sutherland

Notions of 'flow', 'fluidity', and 'liquidity' have become commonplace metaphors for distinguishing today's mobile, globalized world-system from that of previous eras. Our 'society is constructed around flows,' states Manuel Castells (2010: 442), who is surely most responsible for popularizing such an image: 'flows of capital, flows of information, flows of technology, flows of organizational interaction, flows of images, sounds, and symbols. Flows are not just one element of the social organization: they are the expression of processes dominating our economic, political, and symbolic life'. This concept is remarkably common within social theory, appearing in the work of Manuel DeLanda (1992), Stephen Bertman (1998), Zygmunt Bauman (2000), Michael Hardt and Antonio Negri (2000), John Urry (2000), Scott Lash (2002), Steven Shaviro (2003), and Christian Fuchs (2011), amongst many others. In all of these cases, flows are, as John Tomlinson (2007: 75) argues, 'deployed to grasp the social ontology of recent modernity' - that is, they are used:

to comprehend, variously: the permeable, protean nature of social space; the intrinsic mobility both of agents and of social processes and relations (as in the flows around a network); and the phenomenology of modern social existence. This latter, not only in terms of the common experience of mobility and deterritorialization, but also in terms of the constant dissolution of fixity in value, and of a different "texture" of life.

It is this ontologization of fluidity that I designate the metaphysics of flux, a concept that I will examine further throughout the course of this article. The term 'metaphysics' is used here as Kant (2004: 15) defines it, that which is 'based upon neither outer experience, which constitutes the source of physics proper, nor inner, which provides the foundation of empirical psychology'. In other words, that which lies beyond all human ability to directly perceive it. Whilst I largely agree with Jacques Derrida's critique of the metaphysics of presence, my intention is not to deconstruct the concept of metaphysics as a whole. Rather, I argue that metaphysical arguments must be recognized as such, so that they can be judged on their own merits; as Latour (2005: 51) argues, social theorists too often abstain altogether from engaging with metaphysics, instead attempting to cut 'all relations with philosophy, that fanciful and non empirical discipline which represents the lowly infancy of the now mature social sciences'. Yet in my view, the very notion of flows is almost entirely metaphysical in content.

In this article, I will posit that the metaphysics of flux is not problematic because it is metaphysical in nature, but rather, because it attempts to theoretically substantiate the empirical observation of increased speed and mobility through a series of broad, and often unjustifiably ahistorical ontological propositions. In doing so, it unjustly privileges the category of becoming over that of being, and as a result, both reifies an ideology of immateriality that does not adequately reflect the material nature of production and distribution, and makes it difficult to conceive forms of political praxis that do not further entrench the accelerating tendencies of the network society. The metaphysics of flux brackets out the importance of stasis in understanding our world: on the one hand, that of objects, whose existence is inherently substantial despite the changes that may occur to them over time, and on 
Thomas Sutherland, 'Liquid Networks and the Metaphysics of Flux: Ontologies of Flow in an Age of Speed and Mobility',

the other, the human capacity for reason, and our ability to create universal categories in order to rationally assess our lifeworld.

At best, argues A.N. Whitehead (1978: 13), a metaphysical system 'will remain only an approximation to the general truths which are sought'. We cannot return to a pre-Kantian metaphysics in which it is seen to be possible to derive universal truths from subjective observations of fact; we must recognize the inevitable limits of human cognition. At the same time, however, this should not preclude us from discussing metaphysics altogether; otherwise, it becomes too easy to fall into the trap of an anthropocentric empiricism that fails to recognize the phenomenological contingency of space and time, and thus treats the correlation between human perception and the world as if it somehow reflects the full reality of the world in itself.

\section{The accelerating temporality of the network society}

'We do not know what a body can do...' This is how Gilles Deleuze (1988: 17) frequently summarizes Benedict de Spinoza's (1955: 132) argument that 'no one has hitherto laid down the limits to the powers of the body'. For Deleuze, this is an immensely liberating statement - it exemplifies the Spinozist notion that a being's essence is contingent, consisting of nothing more than its power to act. Whilst rarely discussed in such a context, Spinoza (1955: 130-138) can in fact be viewed as the first modern philosopher of media - the 'human body can be affected in many ways,' he writes, 'whereby its power of activity is increased or diminished'. Spinoza recognized the way in which the body's power is both constituted in and augmented by its relations with other material beings. Yet as Marshall McLuhan (1964: 49) demonstrates, such an extension of the human body does not necessarily increase its power uniformly - for every extension, there is an amputation.

In the case of networked, digital media, the capacity to extend our productive abilities carries with it a substantial cost. For the more tasks we are forced to focus upon, the more our ability to rationally comprehend and speculate about the world around us is amputated. A network society is heavily reliant upon speed and mobility - the ability to rapidly transport people, data, and goods becomes an economic necessity in a social formation that increasingly expects instantaneous gratification. We have, accordingly, developed a culture that fetishizes efficiency, flexibility, and above all, speed, driven by the unchallenged assumption that a continuous increase in the productive capacity of labour is not only synonymous with progress, but is necessary for continued prosperity - and as a result, both producers and consumers are thrown into an environment that demands the open-ended acceleration of all aspects of our lives (Hassan, 2009: 19-20).

In the earliest days of the Industrial Revolution, Adam Smith (1999: 368) observed that the 'man whose whole life is spent in performing a few simple operations, of which the effects too are, perhaps, always the same, or very nearly the same, has no occasion to exert his understanding'. For Smith, the downside to the division of labour that so tremendously extended the productivity of the unskilled labourer was that it engendered an industrial environment in which workers were offered no opportunity to engage in the kind of speculative thought that enriches everyday life. In a case of remarkable irony, today, almost the exact opposite circumstances exist, and yet the outcome is largely the same. Our cognitive capacity for reasoning and contemplation is stunted by a demand for everincreasing efficiency in a plethora of diverse tasks, and thus, our attention span and faculty for concentration erode. We have abandoned what Josef Pieper (1998: 54) defines as the very essence of 
Thomas Sutherland, 'Liquid Networks and the Metaphysics of Flux: Ontologies of Flow in an Age of Speed and Mobility',

Theory, Culture \& Society. 30 (5): 3-23.

http://tcs.sagepub.com/content/30/5/3

leisure, that being 'the power to step beyond the working world' and devote time to quiet, uninterrupted thought.

Is it possible that we as humans have reached the threshold to which we are able to gainfully extend ourselves? What if there is actually a limit to what the body can do? Technology is never neutral - in utilizing various technologies in order to extend our experience of time, that very experience becomes a property of the technology itself (McLuhan 1964: 51). ICTs do not simply reflect the phenomenological experience of time; rather, they produce it. The ideology of speed is an ideology produced not just by humans, but by the objects with which we interact as well. Consequently, the 'timescape' of our lifeworld, as Barbara Adam (1998) terms it, has been profoundly affected. As more and more activities are piled upon us, our conscious experience of time in the world starts to resemble one continuous present - we become unable to think the future in any terms other than those of panic (Green, 2002: 284). This change, and the rapidity at which it has occurred, demonstrates the urgent need for continued study into the ways that our quality of life has been affected by such developments. Yet in doing so, we need to take care to ensure that we do not normalize the very same assumptions that have produced this fetishism - hence why I believe it important to examine the metaphor of fluidity.

\section{Ontologizing flux}

Heraclitus of Ephesus is generally regarded as the first philosopher of flux. Most famously, he is cited as claiming that for 'those who step into the same rivers, different and again different waters flow' (Curd, 2011a: 45). It is easy to read this as suggesting that the world exists in a state of constant metaphysical flux; one in which there is no stability from which we can infer the existence of objects. Yet in acknowledging that these are 'the same rivers', Heraclitus actually seems to affirm the continuity of objects in spite of the constant change that they undergo. Heraclitus' view of the kosmos is dialectical: the flux that we encounter in our sensory perception is offset by the logos - the eternal rational structure that underpins the world, and which can be apprehended through reason (Curd, 2011b: 15-16). It was Plato, however, who first defined this tension in terms of being and becoming. In Timaeus (2008: 18), the book's namesake asks: 'What is that which always is, and has no becoming, and what is that which is always becoming but never in any way is?' He answers this rhetorical question by suggesting that 'the one is apprehensible by intelligence with an account, being always the same, the other is the object of opinion together with irrational sense perception, becoming and ceasing to be, but never really being'. Thus, in Plato's metaphysics, being represents the eternal Forms, whilst becoming represents the faulty realm of sensory perception.

In recent years, radical philosophies - generally inspired by Gilles Deleuze and Félix Guattari's two major works: Anti-Oedipus (1983) and A Thousand Plateaus (1987) - have often attempted to eliminate this tension in its various forms by embracing the primacy of becoming, and thus dismissing the static qualities of objects as illusionary, and sometimes even reactionary, products of the human intellect (Harman, 2011: 24). As Peter-Paul Verbeek (2005: 2) rather dryly puts it, 'now that we have survived the death of God and the death of the subject, we seem to be faced with the death of the thing'. Eliminating the tension between being and becoming, these theorists emphasize the role of a pre-individual flux from which objects emerge. It is not my desire in this article to question the importance of becoming; but rather, I wish to understand it as the primary component of being, rather than as a presupposition of it. I propose that in importing these metaphysical principles in order to substantiate empirical arguments, the metaphysics of flux reifies, ontologizes, and thus normalizes the 
Thomas Sutherland, 'Liquid Networks and the Metaphysics of Flux: Ontologies of Flow in an Age of Speed and Mobility',

Theory, Culture \& Society. 30 (5): 3-23.

http://tcs.sagepub.com/content/30/5/3

primacy of process, and thus, inadvertently plays into some of the most damaging hegemonic ideals of the network society.

Before continuing, it is important to emphasize that the image of flows and fluidity is not always inappropriate, although I would suggest that it needs to be used with a greater degree of caution. It is hard to avoid the fact that at a purely material level, information is primarily transported today through quite literal flows of electrical energy. Digital networks have allowed for a virtually endless flow of data, media, and capital to be transmitted around the globe at the speed of light. In these cases, which are essentially empirical, rather than metaphysical, discussion of flow is entirely accurate, and quite often useful. Our lifeworld is today, more than any other time in history, constructed within assemblages of constantly flowing matter and energy. Likewise, there is still a great deal of rhetorical power in utilizing the metaphor of flows - as our lives are continuously sped up by the tireless motor of productivity, we have less and less possibility of being able to rationally comprehend the assemblages within which we are situated.

Metaphor cannot be avoided in the study of philosophy - as Whitehead (1978: 4) emphasizes, the language of metaphysics can never become more than that of metaphor, as it requires words to 'be stretched towards a generality foreign to their ordinary usage'. The metaphor of rapidly moving flows quite effectively depicts the way in which the actors that construct our lifeworld within the network society seem to pass by so quickly that they become almost imperceptible, impeding our rational ability to reflect upon our experience of the world. The key thing to remember, though, is that this is still just a metaphor - it is only really useful as a catalyst for further metaphysical speculation, it does not represent the full totality of potential experience (Bogost, 2012: 72). If we posit that these flows have had a deleterious effect upon our lives, then we must use this metaphor to counterpose it against an image of how we would like the world to exist. This kind of speculation is what Herbert Marcuse (1991: 13) refers to as 'the power of negative thinking - the critical power of Reason'.

Yet in the work of the aforementioned theorists, it does a lot more than simply operate as a negative metaphor: it becomes the ontological basis - the very ground of reality - for the economic, social, and political functioning of the network society. This is highly problematic. In spite of how commonly utilized an image it is, there is surprisingly little tangible explanation of what these flows are, and why this metaphor is even appropriate. Castells (2010: 442), for example, states that flows are, by his definition, 'purposeful, repetitive, programmable sequences of exchange and interaction between physically disjointed positions held by social actors in the economic, political, and symbolic structures of society'. This is a remarkably abstract and mundane explication of a concept that he relies upon so heavily - his lack of engagement with the metaphorical import of such a term is frustrating, as is his failure to explain what differentiates these flows from the kinds of social mediators that have existed throughout history. Castells generally backs up his findings with impressive levels of research, which makes the absence of any sophisticated theorization of this concept all the more disappointing.

Bauman (2000: 2), on the other hand, spends a significant amount of time analyzing the metaphor, explaining that 'liquids, unlike solids, cannot easily hold their shape. Fluids, so to speak, neither fix space nor bind time'. Likewise, in one particularly literal example, Stephen Bertman (1998: 122) uses the fluid mechanics of eighteenth-century Swiss mathematician Daniel Bernoulli as the basis of a discussion of postmodern society. Yet as Boulton et al. (2012: 198) suggest, these kinds of literal application of the metaphor of fluidity is not at all accurate when simultaneously emphasizing the 
Thomas Sutherland, 'Liquid Networks and the Metaphysics of Flux: Ontologies of Flow in an Age of Speed and Mobility',

discontiguity of flows in an Information Age supposedly divested of a necessary or even predominant basis in geographic continuity'. If flows transcend all borders, does this really fit with the emphasis upon fragmentation and plurality in these theorists' works?

The metaphor of fluidity tends to act as a substitute for more effective methods of discussing the network society - as Ned Rossiter (2006: 21) argues, the 'so-called openness, fluidity, and contingency of networks is rendered in essentialist terms that function to elide the complexities and contradictions that comprise the uneven spatiotemporal dimensions and material practices of networks'. The metaphysics of flux overly abstracts the lived conditions of our existence - in prioritizing mobility, speed, and immateriality, it obscures the situated materiality and substantiality of the individual actors (whether human or non-human) within the world. The problem with discussions of global fluidity, regardless of what it is that is supposedly flowing, is that they ignore the agency of these actors - flows are presented as somehow weightless, even when they are composed of relations between objects that are anything but (Van Dijk, 2006: 101).

\section{The objectivity of digital media}

Digital information, even when transmitted in the form of electrical energy, does not just constantly flow, but rather, is composed of objects; objects that are the products of labour. The term 'objects' is used here as synonymous with 'actors' and 'beings' - to exist is to be, and as Levi Bryant (2011b: 263) argues, 'to be is to make or produce differences'. To be is to have an effect upon the world - that is, to effect positive difference - and thus, everything that exists is by definition an object. Under such a theory, the process of objectification does not occur solely through human recognition, but rather, is the very presupposition of existence. This is an ontological argument, following Aristotle's (2001: 731732) definition of an investigation into 'being as being and the attributes which belong to this in virtue of its own nature'; the discovery of those elements that 'must be elements of being not by accident but just because it is being'.

The concept of 'substance' is used here in its most traditional sense: in Aristotle's (2001: 9) terms, 'that which is neither predicable of a subject nor present in a subject'; i.e. that which forms of the basis of the individual being. Substance 'is not something that can anywhere be found in experience,' argues Bryant (2011a: 85), 'but is rather an irreducible ontological premise necessary if our commerce with the world and experimental activity is to be intelligible'. This is not to imply an atomistic view of the world, in which all objects are composed of the same matter, nor is it to suggest that objects cannot differ in degrees of power, but rather, to simply argue that all objects share one universal characteristic: to exist. This notion, which forms the basis of what Bryant terms 'onticology' - developed divergently from the object-oriented philosophy of Graham Harman (2002) - has the potential to provide us with a valuable method for discussing our increasingly crowded mediascape, and for analysing the concept of the network society without unnecessarily privileging the metaphysics of flux. Following Mark Deuze's (2011: 137) suggestion that we need to engage with a 'perspective on life lived in, rather than with, media', I view the object-oriented approach of onticology as opening up the valuable possibility of a neo-Spinozism that focuses upon the autonomy and irreducible complexity of being as substantiated through the contingent power to act. A Spinozism informed by the temporal and relational innovations of process philosophy and actor-network theory, rather than focusing one-dimensionally upon the political possibilities within the production of desire, as many post-Deleuzian perspectives have tended toward. 
Thomas Sutherland, 'Liquid Networks and the Metaphysics of Flux: Ontologies of Flow in an Age of Speed and Mobility', Theory, Culture \& Society. 30 (5): 3-23.

http://tcs.sagepub.com/content/30/5/3

An object-oriented perspective is ontologically realist: it presupposes both the existence of a world independent of human thought, and the ontological reality of all entities (Braver, 2007: 15). It is not, however, epistemologically realist - it acknowledges that the human ability to think objects external to us does not in turn allow for a direct correspondence between thought and being. The reason that I view such an approach as valuable is not because I perceive it as grasping the truth of the objective world in itself, nor because I contend that ontology should be the sole basis of politics - the deleterious effects of the network society upon the human capacity for thought are issues primarily phenomenological in nature. Rather, it is because any epistemological or phenomenological perspective - even that of a solipsist - necessarily presupposes an ontology; as soon as one starts talking about the existence of objects, whether one believes that they exist independently of human thought or not, one is discussing ontology (Bryant, 2011: 265).

The question is, then: in studying the politics of media, do we confine ourselves to the question of mediation between the human mind and an unknowable thing in itself, or do we work under the logical, if perhaps undemonstrable, premise that we can think beings external to our own mind? If the answer is the latter, then the discussion must shift to the question of what form these beings take. Theories of mediation from McLuhan onward are predicated upon the ontological existence of objects external to the human subject - objects that have capacities beyond human intentionality, and which in turn alter our phenomenological perception of the world. A practical metaphysics, therefore, can be a valuable contribution to any politics of media. What an object-oriented approach provides is a decentering of the human subject - the acknowledgement of the individual human as an object in a world composed of objects - and thus, a conception of human politics that engages with the alterity of a multitude of non-human actors.

McLuhan (1964: 8) argues that 'the "content" of any medium is always another medium'. Television is a medium, for instance, but so are the images, sounds, and signs that it transmits. Whilst his focus upon media as an extension of the human senses and body means that McLuhan's work is generally read as phenomenological in nature, his contention that the content of any medium forms its own distinct medium suggests an ontological univocity of media in which mediation is not a quality exclusive to a specific class of objects, but rather, is a temporal process within which all objects are implicated; and yet simultaneously, one where an object can never simply be reduced to the medium through which it is transmitted, or vice-versa (Bogost, 2006: 36). One can then infer that all media must have some kind of substantial existence separate from any other media by which they are mediated - if, as McLuhan (1964: 19) argues, 'the effect of the movie form is not related to its program content', then it is logical to suggest that the existence of that content must not be entirely reliant upon the existence of the movie, but instead, has some degree of ontological independence - hence why McLuhan contends that 'the content of a movie is a novel or a play or an opera'. The content can be separated from its medium without losing its qualities as content, and thus, it is logical to deduce that these two media must be regarded as separate objects, although temporally implicated within a single assemblage of mediation.

Following this line of argument, digital information can be said to exist in its own right, apart from any mode of transmission - it has a substantial reality of its own simply in its ability to affect other objects. Yet at the same time, it is essential to emphasize that objects of digital information do not float in the ether, but exist as real, electrical signals, transmitted through computer networks that are profoundly material, comprising computers, modems, routers, phone lines, servers, fibre-optic cables, 
Thomas Sutherland, 'Liquid Networks and the Metaphysics of Flux: Ontologies of Flow in an Age of Speed and Mobility',

etc. - objects that are also produced, typically by a globalized labour force that encounters working conditions little different to those of any prior era of industrialization (Cubitt, 2008: 134; Gies, 2008: 313; Nevarez, 2011: 61). Even the information itself is produced - whether this production occurs through the labour of human workers, or is the result of computer automation is irrelevant - and hence the result of material processes.

The use of computerized distribution chains, including RFID (Radio Frequency Identification) tags and containerized docks, has created a global marketplace in which it is increasingly difficult to identify any commodity - even the most basic ones, such as chairs and tables, that one would generally think to exist completely outside the realm of digital information - that has not been affected by a general hegemony of computerization. The intermodal transportation of goods is now coordinated primarily through a complex network of computers, and cargo is standardized - and thus digitized through the use of uniform shipping containers. The very process of distribution, in other words, is reduced to a stream of digital objects (Fuller, 2005: 95; Cubitt et al., 2011: 153). Automated labour at all levels of industry means that information does not need to be produced by people in order to be produced. Thus, on three levels the metaphysical reality of digital information is affirmed: as information in its own right (i.e. as an object that produces difference); as an object mediated by physical mechanisms of transmission; and as the result of material practices of production.

\section{The abstraction of fluidity}

We need to evaluate the objects that affect our lifeworld in terms of both their material effect, i.e. the difference that they produce, and the objects through which they are mediated, mobilized, and distributed. Sean Cubitt (2005: 197) argues that distribution systems tend to be underanalysed, or simply ignored in most studies of globalization, and thus take the form of a 'black box' - that is, a complex system which is treated as nothing more than an input and an output, with no examination of its inner workings and the objects with which it is constituted (Latour, 1987: 2-3). This demonstrates how crucial it is that we avoid generalizing the multitude of ways in which objects are mobilized. The metaphysics of flux is an excellent example of what Harman (2011: 25) terms 'undermining'. 'Undermining occurs,' he proposes,

if we say that "at bottom, all is one" and that individual objects are derivative of this deeper primal whole. It happens if we say that the process of individuation matters more than the autonomy of fully formed individuals. It also happens when we say that the nature of reality is "becoming" rather than being, with individuals just a transient consolidation of wilder energies that have already moved elsewhere as soon as we focus on specific entities.

The emphasis upon rapid change in discussion of flows undermines the materiality, agency, and diversity of the objects within them, and thus, makes it difficult to discuss the myriad of ways in which different objects produce and affect us. It privileges the concept of becoming to the degree that one begins to question whether autonomous objects can exist at all on an ontological level. It is easy to argue that things exist within a constant state of fluidity; the more difficult argument is in justifying why, in denying these things any objectively stable sense of existence, they would actually emerge as objects in the first place. If there is no preexisting alterity within a flux - one that would necessarily imply the existence of more than one object - then how could objects, including the human subject, ever be said to emerge? If the entire universe consists of nothing but a formless void of matter-energy, 
Thomas Sutherland, 'Liquid Networks and the Metaphysics of Flux: Ontologies of Flow in an Age of Speed and Mobility', Theory, Culture \& Society. 30 (5): 3-23.

http://tcs.sagepub.com/content/30/5/3

then there are two ontological choices one can make: either you accept an absolute monism of undifferentiated flux that provides no explanation for how objects could crystallize without the intervention of a transcendent entity, either God or an autonomous Cartesian thinking substance; or you acknowledge that there must be some form of difference already present within this flux, and thus return to an Aristotelian conception of substance that recognizes the existence of individual objects (Harman, 2010: 9; Bryant, 2011b: 272).

It is worth noting that, within the domain of media studies, the concept of flow has traditionally been most associated not with mobility and distribution in a general sense, but specifically with Raymond Williams' (2003: 77) discussion of television audiences, in which he distinguishes between 'the static concept of "distribution"' and 'the mobile concept of "flow". Williams' suggestion that the immediacy and effect of the televisual medium comes in large part from the way in which the broadcast texts appear to form one continuous, indivisible sequence has seen a number of important of critiques since it was first published. John Ellis (1982: 117), for instance, notes that in spite of our perception of such a flow, items broadcast 'are still separate texts, independent works like a cinema film', and thus need to be thought of in terms of segmentation, as well as flow. Likewise, Jane Feuer (1983: 15-16) argues that such a flow 'is pure illusion', suggesting that 'it would be more accurate to say that television is constituted by a dialectic of segmentation and flow'. Importantly, she notes that flow, 'as a seamless scanning of the world, is valorized at the expense of an equally great fragmentation'. Within the context of the specific medium of television, Feuer articulates one of the key problems with the metaphysics of flux: as soon as you accept that there are individual objects within a flow (as Williams does), then what we perceive as flow can just as easily be perceived as segmentation - the exact opposite!

However, whilst the critique of televisual fluidity has a long legacy within media studies, the same cannot be said for social theory as a whole - particularly in regards to other forms of mediation. There are indisputably many different types of flows that can be observed, yet in most theorists' work, little effort is put into explaining the equivalence between them. When Fuchs (2011: 129-130) describes 'a space of global flows of capital, power and ideology that create and permanently recreate a new transnational regime of domination', is this meant to be seen as commensurable with his prior description of flows of 'money, commodities, people and information'? Perhaps capital, ideology, and information do metaphorically flow, in the sense that they are able to permeate, and thus mediate, almost every element of our lifeworld at a rate far greater than human perception. I would also argue, however, that they are generally the product of social structures with at least some level of fixity. On the other hand, the transportation of goods will always require some degree of segmentation - the containerization of distribution chains, whilst allowing for more efficiency movement, makes obvious the way in which such a system is defined by the often uneven flow of its objects, rather than by a continuous stream of emergence or becoming.

Similar problems occur when Castells (2010: 453) argues that the 'space of flows does not permeate down to the whole realm of human experience in the network society. Indeed, the overwhelming majority of people, in advanced and traditional societies alike, live in places'. It is never clearly established how this space of flows substantially differs from any prior social formation, and there is little clear indication of why the space of flows should be seen as distinct from the space of places with which he contrasts it, considering the ubiquity and materiality of contemporary digital networks. It is interesting to consider that Castells (2010c: 459) perceives a small minority of people as 
Thomas Sutherland, 'Liquid Networks and the Metaphysics of Flux: Ontologies of Flow in an Age of Speed and Mobility',

not living in 'places' - an argument that echoes Marc Augé's (1995) concept of 'non-places'. Even if we accept that the 'dominant tendency is toward a horizon of networked, ahistorical space of flows, aiming at imposing its logic over scattered, segmented places, increasingly unrelated to each other', this does not at all negate the existence of place; rather, it simply changes the phenomenological experience of those situated within it. Across the globe, wealth and power is, as it always has been, disproportionately concentrated within a distinct propertied class whose opportunities in life are advantaged through inequitably funded education systems and a nepotistic culture of corporate management. The entrenchment of this power has nothing to do with any space of flows; it is the perpetuation of a system of capital accumulation that has been developing from the industrial revolution onward (Webster, 2006: 119).

In assuming a general commensurability between different types of flow, the metaphysics of flux establishes an ontological universality that is simply unjustified. The 'specificity' of mediators, as Latour (2005: 39) argues, 'has to be taken into account every time'. How exactly does ideology flow? Does it flow in the same way that power or capital flows? Is the flow of migrant workers across national borders in any way equivalent to the flow of information through fibre-optic cables? In attempting to establish a figurative explanation for how the world-system of today differs from those of the past, the metaphor of fluidity has been stretched beyond the limits of credibility - it universalizes the diverse and contingent mobilities of disparate social actors (Last 2011: 76). The metaphysics of flux reifies, rather than challenges 'the acceleration of a common reality,' as Paul Virilio (2007: 9) puts it, 'that not only outstrips us in tyrannical fashion, but literally outpaces all objective evaluation and thereby all understanding'. If we do not acknowledge the inherent materiality and substantiality of the network society's infrastructure, then we effectively forfeit the ability to identify the potential sites for political praxis within it.

\section{Normativity and the myth of friction-free capitalism}

Fluidity, distilled to its simplest form, represents speed and mobility. Yet at the same time, it implies a lot more than this - it suggests weightlessness, immateriality, and most importantly, inevitability. It connotes a lack of finitude - as John Urry (2000: 32) argues, a liquid will 'take different forms as it gorges within, or trickles through, any particular region'. Therefore, I contend that the metaphysics of flux hinges upon two axiomatic assumptions: firstly, that flows have always existed in some form, as otherwise the world would exist in complete stasis; and secondly, that today's society has unleashed and accelerated these flows to an unprecedented degree. The result is that the status quo comes to appear as inevitable.

If flows have always existed in some form, and yet at the same time, these same flows today represent the basis of globalized capitalism, then it would seem clear - recalling the assertion of Deleuze and Guattari (1983: 154) that 'capitalism has haunted all forms of society' - that capital has also always existed, however embryonic. Yet this is a backward step - in the Grundrisse, Marx (1973: 86) describes the erroneous assumption of his contemporary political economists that capital is a general, eternal quality of nature', arguing that this belief works to justify and naturalize 'the eternity and harmoniousness of the existing social relations'. Just as production existed prior to any conception of capital, mobility and speed do not naturally lead to this concept of flow.

It is important that we avoid the empiricist tendency to view our ever-accelerating timescape as reflecting some kind of unavoidable change in the nature of reality - instead, it needs to be viewed as 
Thomas Sutherland, 'Liquid Networks and the Metaphysics of Flux: Ontologies of Flow in an Age of Speed and Mobility', Theory, Culture \& Society. 30 (5): 3-23.

http://tcs.sagepub.com/content/30/5/3

the result of a specific spatio-temporal mediation that is produced in our relation with new technologies of communication. The metaphysics of flux does not simply reflect things 'as they are' - rather, following Latour's (1993: 72) contention that the very idea of 'a continuous flow' is 'generated only when we bind together the cohort of elements that make up our day-to-day universe', it is the result of an increasingly prevalent temporal incertitude; the loss of ability to apprehend an increasingly dense mediascape (Deuze 2011: 137). The image of endlessly moving and accelerating flows, particularly when augmented with discussion of complex systems/chaos theory (as occurs in the work of DeLanda, for instance), causes capitalism to come to be seen as autonomous, self-organizing, uncontrollable, and inevitable (Robins and Webster, 1999: 67). When we see such flows as inevitable, our capacity to think possibilities outside of their logic dissipates. The metaphysics of flux offers no explanation for the agency of objects, and thus, makes the accelerating tendencies of the network society seem unremarkable and predetermined. It becomes just another contributor to the cultural environment of what Mark Fisher (2009: 2) calls 'capitalist realism' - the sense 'that not only is capitalism the only viable political and economic system, but also that it is now impossible even to imagine a coherent alternative to it' (Fisher, 2009: 4).

The ideology of the free flow of information has long been used by the United States as a means to entrench its own global hegemony, enable the proliferation of surveillance and intelligence networks, and perpetuate the dominance of the American communications industry - by flattening out the uneven distribution of power that characterizes any study of political economy into a smooth space of flows, the very self-image of capital that is promulgated through its processes is further replicated and entrenched, whilst the sovereign nation-state continues to persist unperturbed (Schiller, 1999: 71; Noys, 2010: 125). The 'incentive to create the world market, to reduce spatial barriers, and to annihilate space through time is omni-present,' argues David Harvey (1989: 232), 'as is the incentive to rationalize spatial organization into efficient configurations of production'. The very idea of a fluid, immaterial economy is a mythological construct - a myth 'of a transparent society in which the movement of information is no longer mediated' (Campanelli, 2010: 38). Why is it logical to assume, in an economy built upon the belief that information transcends all barriers, that free flows would be the basis for any emancipatory project? Perhaps, when faced with the threat of such a totalizing force, what we need is to stake out sites of resistance into which such flows cannot enter. Rather than following Hardt and Negri (2000: 206) in arguing that we 'must push through Empire to come out the other side', perhaps we need to rearticulate the importance of political sovereignty in enabling an autonomy of praxis outside the realm of capital.

There is an unsettling connection between such dreams of a rhizomatic network society built upon speed, mobility, and the supposedly liberating possibilities of endless lines of flight and the values of neoliberal capitalism. As Scott McQuire (2008: 105) suggests, 'de-territorialization and acceleration are fundamental attributes of capitalist expansion. While increased mobility has undoubtedly disturbed traditional social and political arrangements, thus generating the potential for radical change, it guarantees neither the direction nor the outcome'. The network society may seem to offer us unrivalled freedom of choice, but without the ability to carefully and considerately reflect upon these choices, who is to say that they will be beneficial? In attempting to present information as something that flows, argues Latour (1993: 118), the 'tracers become more difficult to follow, their cost is no longer so well documented, and one risks losing sight of the bumpy path that leads from the local to the global. So the ancient philosophical category of the universal radically different from the contingent circumstances is applied to them'. 
Thomas Sutherland, 'Liquid Networks and the Metaphysics of Flux: Ontologies of Flow in an Age of Speed and Mobility',

The clear delineations and schisms between demographics that traditionally characterized capitalist societies have been replaced, we are told, by a smooth space in which, according to Urry (2000: 41), 'it is not possible to determine identities once and for all, since a fluid world is a world of mixtures'. Putting aside the awkwardly literal nature of such a metaphor, this focus is problematic for two reasons. Firstly, it ignores the very real material limitations that still impede identity formation within the network society, thus allowing for little meaningful analysis of power dissymmetries. Secondly, it fetishizes the nomadic subject, falsely and superficially conflating mobility and fluidity of identity, whilst not taking into account the possibility offered by Fisher (2009: 28) that "flexibility", "nomadism" and "spontaneity" are the very hallmarks of management in a post-Fordist, control society' - the risk that there is no alterity in such a subject, and thus, no potentiality for altering the system that has produced it.

In ontologizing the metaphor of flow, we risk further normalizing the ideology of 'friction-free capitalism', which Slavoj Žižek (2004: 803-804) describes as the fantasy of an 'ethereal' globalized market system completely uninhibited by 'material inertia'. As Cubitt (2007: 308) acutely identifies, when 'cultural critics as alert as Paul Virilio describe communication as instantaneous, not only do they deny the materiality of mediation, they fall into an ideological trap laid precisely by the administration. Discourse that surrenders to the ideology of light-speed communication presents as normative the proposition that the present is always already documented - represented, distributed, consumed, and past.' The fact that something can travel very, very quickly does not make it instantaneous - the frustration that so many of us experience during even the split-second interface delays of today's gadgets demonstrates this.

In discussing digital transmission as if it were instantaneous, we fail to recognize both the moments of fragility inherent within the infrastructure, and the way in which these technologies actually produce, rather than reflect our timescape. 'The rhetorical force of the association of speed with progress,' argues Tomlinson (2007: 23), 'its appeal to a general human aspiration for betterment and an impatience with circumstances that are "holding us back" - is pervasive of modern political discourse'. Any theoretical perspective that sees it self as politically emancipatory must be able to account for this hegemony of mobility and speed - 'a hegemony dominated by a faith in net communication as immediate and the concurrent' - and the normative problems that come along with it (Munster, 2001: 14).

Globalization, argues Doreen Massey (2005: 87), 'installs an understanding of space, the "space of flows", which, just like the space of places in modernism, is deployed (when needed) as a legitimation for its own production and which pretends to a universality which anyway in practice it systematically denies'. The metaphysics of flux provides an appealing, easily graspable image, useful for rhetorical purposes, and yet at the same time, it actually fails to elucidate the problems that we face. We must seek to challenge the narrative of globalization - a narrative of 'total unfettered mobility; of free unbounded space', and acknowledge the 'chaos of different spatio-temporalities' through which our lifeworld is constructed (Massey, 2005: 81; Harvey, 2009: 155). We must denaturalize the temporal monism of the network society, and come to recognize the importance of preserving the diverse temporal rhythms upon which our lives are grounded.

\section{An appeal for stasis}


Thomas Sutherland, 'Liquid Networks and the Metaphysics of Flux: Ontologies of Flow in an Age of Speed and Mobility', Theory, Culture \& Society. 30 (5): 3-23.

http://tcs.sagepub.com/content/30/5/3

Object-oriented ontology is based upon the fundamental premise of alienation - objects, including humans, are inherently and ineluctably alienated not only from other objects, but also from themselves (Bryant, 2011a: 85; Morton, 2011: 177). This in turn means that speculative metaphysics, of the kind deemed by Kant (2004: 90) to have lulled philosophy into a 'dogmatic slumber', takes on a new and vitally important role. The fact that objects are never fully present - part of their essence always withdraws from contact - provides a new potentiality for reason and speculation, as it emphasizes the impossibility of any metaphysical perspective grasping the irreducible essence of an object. What we need to avoid is domesticating the object in advance - i.e. prejudging its qualities - and instead embrace all objects in their infinite metaphysical alterity (Morton, 2011: 166). 'By providing the basis for an understanding of the place of humanity in the cosmos,' writes Arran Gare (1993: 97), 'a metaphysical theory must then also serve as the foundation for the practical sciences: ethics and politics, and for the productive sciences. By doing so, metaphysical ideas can become incorporated into the social and physical worlds of people as a major component of what is taken as common sense, and so can become a major determinant of the way people live their lives'. Unfortunately, when one ontologizes the flux of global capital, then it can quickly come to seem inescapable, and in turn, the political possibilities of mindfulness, contemplation, and speculative reason at an individual level are obscured (Hassan, 2012: 164).

It is regrettable that Heraclitus' distinction between flux and logos is so often neglected in discussions of political praxis. The political dichotomy in which stasis is automatically seen as the antithesis of progressiveness is no longer relevant - we need some degree of stasis in order to be able to develop political strategy (Debray, 2007: 20-22). We need to be able to think the political possibilities of stasis, which comes from our faculties for rational thought. For Whitehead (1929: 23, 51), speculative reason - which he refers to as 'the practical embodiment of the urge to transform mere existence into the good existence, and to transform the good existence into the better existence' - is essentially 'un-trammelled by method. Its function is to pierce into the general reasons beyond limited reasons, to understand all methods as coordinated in a nature of things only to be grasped by transcending all method'. The study of metaphysics is politically important, not because it allows us to reflect upon the world as is, but precisely because it opens an immanent critique of such reflections; through metaphysics, we create new categories of representation. Of course political praxis seems hopeless in a world that allows us no time for contemplating our position in the world, and the effects of the numerous assemblages of objects that affect us. Opportunities for the exercise of reason speculative reason - should not be seen as a luxury, but rather, as a necessity.

The alternative - unacceptable in my assessment- is to premise one's political project upon harnessing flows. Hardt and Negri (2000: 45), for instance, frequently contend that we cannot '(re)establish local identities that are in some sense outside and protected against the global flows of capital and Empire'. The problem with this kind of 'accelerationism' - to adopt a term from Benjamin Noys (2010: 5) - is that in attempting to identify a site of agency within the ontological terrain of capital, this very same metaphysical outlook is reified, and thus, the power of negative thought diminished. Whilst by no means as extreme, such theories end up resembling more palatable versions of the posthumanist fantasies of philosophers such as Nick Land (2011), who argue that in order to bring down capitalism, we need to amplify its most destructive elements.

Even in texts that do not explicitly advocate such an outlook, there are implications that could easily lead us down the same path. For instance, when Castells (2010: 446) states that 'the elites do not 
Thomas Sutherland, 'Liquid Networks and the Metaphysics of Flux: Ontologies of Flow in an Age of Speed and Mobility',

want and cannot become flows themselves, if they are to preserve their social cohesion, develop the set of rules and the cultural codes by which they can understand each other and dominate the others', he tacitly affirms one of the most common principles espoused in the metaphysics of flux: the idea that these flows, which by their very nature supposedly escape the confines of both nation-states and capital, are somehow connected to 'the people' rather than 'the elites'. From this, one can easily infer that these flows must therefore hold the key to political progress, even as they make our everyday life more frustrating and alienating. Yet in reality, all this demonstrates is the extent to which the metaphysics of flux has already been normalized - 'the standard cure' for any problem in our society today, states Albert Borgman perceptively (1992: 13), 'is a prescription for hyperactivity'.

'Speed is a great gift,' notes Eriksen (2001: 159), 'until it gets out of hand.' The increased mobility of the present era has provided us with many benefits, yet it has also had a deleterious effect upon our quality of life. Whilst it is common for Spinozists to view desire as being the necessary basis for any radical project of political emancipation, I propose that we need to emphasize Spinoza's rationalist side, and his firmly held belief in the need for understanding, contemplation, and reflexivity as the basis of any ethical or political project. Desire can be something to celebrate, but it can also be something to fight against - it is the human tendency toward addiction that encourages the worst, most exploitative qualities of capital. Our liberation as individuals is contingent upon the possibility of being able to transcend this addiction, through understanding of the ways in which our body is affected, both positively and negatively, by other objects (Fisher, 2009: 73). Spinoza's philosophy is based upon the premise that politics needs thought, and thought requires time. In order to challenge the uncontrollable speed of our contemporary society, we must reject a metaphysics of flux that reifies such accelerating tendencies, and begin to recognize that, as Walter Benjamin (1999: 453) argues, 'the fruits of idleness are more precious than the fruits of labor'.

\section{Bibliography}

Adam, B. (1998) Timescapes of Modernity. London and New York: Routledge.

Aristotle (2001) 'Metaphysics', pp. 689-926 in R. McKeon (ed.) The Basic Works of Aristotle. New York: The Modern Library.

Aristotle (2001) 'Physics', pp. 218-397 in R. McKeon (ed.) The Basic Works of Aristotle. New York: The Modern Library.

Augé, M. (1995) Non-Places: An Introduction to Supermodernity. London and New York: Verso.

Bauman, Z. (2000) Liquid Modernity. Cambridge: Polity.

Benjamin, W. (1999) 'Convolutes', pp. 27-824 in R. Tidemann (ed.) The Arcades Project. Cambridge, Massachusetts: Harvard University Press.

Bertman, S. (1998) Hyperculture: The Human Cost of Speed. Westport, Connecticut: Praeger.

Bogost, I. (2006) Unit Operations. Cambridge, Massachusetts: The MIT Press.

Bogost, I. (2012) Alien Phenomenology, or What It's Like to be a Thing. Minneapolis: University of Minnesota Press.

Borgmann, A. (1992) Crossing the Postmodern Divide. Chicago: The University of Chicago Press. 
Thomas Sutherland, 'Liquid Networks and the Metaphysics of Flux: Ontologies of Flow in an Age of Speed and Mobility',

Theory, Culture \& Society. 30 (5): 3-23.

http://tcs.sagepub.com/content/30/5/3

Boulton, A., S.D. Brunn, and L. Devriendt (2012) 'Cyberinfrastructures and "Smart" World Cities: Physical, Human and Soft Infrastructures', pp. 198-207 in B. Derudder, M. Hoyler, P.J. Taylor, and F. Witlox (eds) International Handbook of Globalization and World Cities. Cheltenham: Edward Elgar.

Braver, L. (2007) A Thing of this World: A History of Continental Anti-Realism. Evanston, Illinois: Northwestern University Press.

Bryant, L.R. (2011) The Democracy of Objects. Ann Arbor: Open Humanities Press.

Bryant, L.R. (2011) 'The Ontic Principle: Outline of an Object-Oriented Ontology', pp. 261-278 in L. Bryant, N. Srnick, and G. Harman (eds) The Speculative Turn: Continental Materialism and Realism. Melbourne: re.press.

Campanelli, V. (2010) Web Aesthetics: How Digital Media Affect Culture and Society. Rotterdam: NAi Publishers.

Castells, M. (2010) The Rise of the Network Society. West Sussex: Wiley-Blackwell.

Cubitt, S. (2005) 'Distribution and Media Flows', Cultural Politics. 1 (2): 193-214.

Cubitt, S. (2007) 'Precepts for Digital Artwork', pp. 304-319 in J. Marchessault and S. Lord (eds) Fluid Screens, Expanded Cinema. Toronto: University of Toronto Press.

Cubitt, S. (2008) 'Virtual Dialectics and Technological Aesthetics', Cultural Politics. 4 (2): 133-154.

Cubitt, S., R. Hassan, and I. Volkmer (2011) 'Does Cloud Computing Have a Silver Lining?', Media, Culture \& Society. 33 (1): 149-158.

Curd, P. (2011) A Presocratics Reader. Indianapolis: Hackett Publishing.

Curd, P. (2011) 'New Work on the Presocratics', Journal of the History of Philosophy. 49 (1): 1-37.

Debray, R. (2007) 'Socialism: A Life-Cycle', New Left Review. (46): 5-28.

DeLanda, M. (1992) 'Nonorganic Life', pp. 129-167 in J. Crary and S. Kwinter (eds) Zone 6: Incorporations. New York: Urzone.

Deleuze, G. (1988) Spinoza: Practical Philosophy. San Francisco: City Light Books.

Deleuze, G. and F. Guattari (1983) Anti-Oedipus. London and New York: Continuum.

Deleuze, G. and F. Guattari (1987) A Thousand Plateaus. London and New York: Continuum.

Deuze, M. (2011) 'Media Life', Media, Culture \& Society. 33 (1): 137-148.

Ellis, J. (1992) Visible Fictions: Cinema, Television, Video. London and New York: Routledge and Kegan Paul.

Eriksen, T.H. (2001) Tyranny of the Moment: Fast and Slow Time in the Information Age. London: Pluto Press.

Feuer, J. (1983) 'The Concept of Live Television: Ontology as Ideology', pp. 12-22 in E.A. Kaplan (ed.) Regarding Television: Critical Approaches - An Anthology. Arlington, Virginia: University Publications of America.

Fisher, M. (2009) Capitalist Realism: Is There No Alternative? Hampshire: Zero Books.

Fuchs, C. (2011) Foundations of Critical Media and Information Studies. Abingdon: Routledge. 
Thomas Sutherland, 'Liquid Networks and the Metaphysics of Flux: Ontologies of Flow in an Age of Speed and Mobility',

Theory, Culture \& Society. 30 (5): 3-23.

http://tcs.sagepub.com/content/30/5/3

Fuller, M. (2005) Media Ecologies: Materialist Energies in Art and Technoculture. Cambridge, Massachusetts: The MIT Press.

Gare, A. (1993) Beyond European Civilization. Bungendore: Eco-logical Press.

Gies, L. (2008) 'How Material are Cyberbodies?', Crime Media Culture. 4 (3): 311-330.

Green, N. (2002) 'On the Move: Technology, Mobility, and the Mediation of Social Time and Space', The Information Society. 18 (28): 281-292.

Hardt, M. and A. Negri (2000) Empire. Cambridge, Massachusetts: Harvard University Press.

Harman, G. (2002) Tool-Being: Heidegger and the Metaphysics of Objects. Chicago and La Salle: Open Court.

Harman, G. (2010) The Quadruple Object. Winchester: Zero Books.

Harman, G. (2011) 'On the Undermining of Objects: Grant, Bruno, and Radical Philosophy', pp. 2140 in L. Bryant, N. Srnick, and G. Harman (eds) The Speculative Turn: Continental Materialism and Realism. Melbourne: re.press.

Harvey, D. (1989) The Condition of Postmodernity. Cambridge, Massachusetts: Blackwell.

Harvey, D. (2009) Cosmopolitanism and the Geographies of Freedom. New York: Columbia University Press.

Hassan, R. (2009) Empires of Speed. Leiden: Brill.

Hassan, R. (2012) The Age of Distraction: Reading, Writing, and Politics in a High-Speed Networked Economy. New Brunswick: Transaction Publishers.

Kant, I. (2004) Prolegomena to Any Future Metaphysics, With Selections from the Critique of Pure Reason. Cambridge: Cambridge University Press.

Land, N. (2011) 'Machinic Desire', pp. 319-344 in R. Mackay and R. Brassier (eds) Fanged Noumena: Collected Writings 1987-2007. Falmouth: Urbanomic.

Lash, S. (2002) Critique of Information. London: Sage.

Last, N. (2011) 'Fluidity: Space, Agency and Order', Space and Flows. 1 (1): 76-85.

Latour, B. (1987) Science in Action. Cambridge, Massachusetts: Harvard University Press.

Latour, B. (1993) We Have Never Been Modern. Cambridge, Massachusetts: Harvard University Press.

Latour, B. (2005) Reassembling the Social: An Introduction to Actor-Network-Theory. Oxford: Oxford University Press.

Marcuse, H. (1991) One-Dimensional Man. London and New York: Routledge.

Marx, K. (1973) Grundrisse. London: Penguin.

Massey, D. (2005) For Space. London: Sage.

McLuhan, M. (1964) Understanding Media. London and New York: Routledge.

McQuire, S. (2008) The Media City. London: Sage.

Morton, T. (2011) 'Here Comes Everything: The Promise of Object-Oriented Ontology', qui parle. 19 (2): 163-190. 
Thomas Sutherland, 'Liquid Networks and the Metaphysics of Flux: Ontologies of Flow in an Age of Speed and Mobility',

Munster, A. (2001) 'Net Affects: Responding to Shock on Internet Time', pp. 9-18 in H. Brown, G. Lovink, H. Merrick, N. Rossiter, D. Teh, and M. Willson (eds) Politics of a Digital Present. Melbourne: Fibreculture Publications.

Nevarez, L. (2011) Pursuing Quality of Life: From the Affluent Society to the Consumer Society. London and New York: Routledge.

Noys, B. (2010) The Persistence of the Negative: A Critique of Contemporary Continental Theory. Edinburgh: Edinburgh University Press.

Pieper, J. (1998) Leisure, the Basis of Culture. South Bend, Indiana: St. Augustine's Press.

Plato (2008) Timaeus and Critias. London: Penguin.

Robins, K. and F. Webster (1999) Times of the Technoculture. London and New York: Routledge.

Rossiter, N. (2006) 'Organized Networks and Nonrepresentative Democracy', pp. 19-34 in J. Dean, J.W. Anderson, and G. Lovink (eds) Reformatting Politics: Information Technology and Global Civil Society. London and New York: Routledge.

Schiller, D. (1999) Digital Capitalism: Networking the Global Market System. Cambridge, Massachusetts: The MIT Press.

Shaviro, S. (2003) Connected, Or What It Means to Live in the Network Society. Minneapolis: University of Minnesota Press.

Smith, A. (1999) The Wealth of Nations: Books IV-V. London: Penguin.

Spinoza, B. (1955) On the Improvement of the Understanding, The Ethics, Correspondence. New York: Dover.

Tomlinson, J. (2007) The Culture of Speed: The Coming of Immediacy. London: Sage.

Urry, J. (2000) Sociology Beyond Societies: Mobilities for the Twenty-First Century. London and New York: Routledge.

Van Dijk, J.A.G.M. (2006) The Network Society: Social Aspects of New Media. London: Sage.

Verbeek, P. (2005) What Things Do: Philosophical Reflections on Technology, Agency, and Design.

University Park, Pennsylvania: The Pennsylvania State University Press.

Virilio, P. (2007) Art as Far as the Eye Can See. Oxford: Berg.

Webster, F. (2006) Theories of the Information Society. London and New York: Routledge.

Whitehead, A.N. (1929) The Function of Reason. Princeton: Princeton University Press.

Whitehead, A.N. (1978) Process and Reality. New York: The Free Press.

Williams, R. (2003) Television. London and New York: Routledge.

Žižek, S. (2004) 'What Can Psychoanalysis Tell Us About Cyberspace?', Psychoanalytic Review. 91 (6): 802-830. 